\title{
The Effectiveness of Subgingival Scaling and Root Planing in Calculus Removal
}

\author{
Guity M. Rabbani, ${ }^{*}$ Major M. Ash, $\dagger$ and Raul G. Caffesse $\ddagger$
}

\begin{abstract}
THIS STUDY PRESENTS an evaluation of the effectiveness of subgingival scaling and root planing related to depth of pocket and type of teeth. A total of 119 teeth in 25 patients were selected; 62 were scaled and 57 were used as controls. All teeth were initially scored using the calculus index of the P.D.I. (Ramfjord). Six surface locations were probed to determine pocket depth. The levels of the gingival margin were marked on the teeth to locate supra and subgingival calculus after extraction. The experimental teeth then were scaled. Both scaled and unscaled teeth were extracted immediately after the experimental procedures. The teeth were washed with water and stained with methylene blue. They were viewed under a stereomicroscope which had a tenth grid on its eyepiece. Percent of surface covered by calculus was assessed on both scaled and unscaled teeth. The results demonstrated a high correlation between percent of residual calculus and pocket depth. It was shown that pockets less than $3 \mathrm{~mm}$ were the easiest sites for scaling and root planing. Pocket depths between 3 to $5 \mathrm{~mm}$ were more difficult to scale and pockets deeper than $5 \mathrm{~mm}$ were the most difficult. Tooth type did not influence the results.
\end{abstract}

Scaling and root planing are the most widely used techniques in periodontal therapy. These procedures are used to remove all bacterial plaque and calculus from the surfaces of teeth. A normal junctional epithelium may be re-established in areas where all the subgingival plaque and calculus have been removed. Studies related to root planing ${ }^{1,2}$ have shown that complete removal of calculus is usually difficult. Despite the best efforts of different clinicians to thoroughly root plane teeth, considerable amounts of calculus remained although the surface felt clinically smooth at the completion of scaling and root planing procedures. Incomplete removal of subgingival plaque has been stated to be equal to no plaque control at all. ${ }^{3}$ It has been observed that complete removal of plaque and calculus is more difficult in deep $^{3,4}$ than in shallow pockets. Hence, the failure in periodontal treatment may be the result of plaque and calculus remaining after therapy. However, quantitative measurement of residual calculus has been limited. The purpose of this study was to determine: (1) Whether any correlation exists between remaining calculus and depth of the pocket; and (2) Whether the type of tooth scaled (anterior or posterior) will influence the amount of remaining calculus.

\footnotetext{
* Formerly Department of Periodontics, The University of Michigan School of Dentistry.

$\dagger$ Professor and Chairman, Department of Occlusion, The University of Michigan School of Dentistry, Ann Arbor, MI 48109.

$\ddagger$ Professor and Chairman, Department of Periodontics, The University of Michigan School of Dentistry, Ann Arbor, MI 48109.
}

\section{MATERIALS AND METHODS}

Twenty-five patients with advanced periodontal disease, with teeth scheduled for extraction, were selected for this study. The total number of teeth included was 119,62 experimental and 57 control teeth. Both experimental and control teeth were obtained from every subject. Prior to extraction, calculus was scored according to criteria of the Calculus Index of the P.D.I. ${ }^{5}$ The Marquis M-1 probe or the No. 3 explorer was used for the detection of subgingival calculus. Pocket or crevice depth was measured from the free gingival margin to the bottom of the gingival crevice or periodontal pocket. Measurements were made with the Marquis M-1 periodontal probe graduated at $3,6,8$ and $11 \mathrm{~mm}$. Measurements were recorded on the buccal, lingual, mesio-buccal, mesio-lingual, disto-buccal and disto-lingual of each tooth. The two measurements recorded on the mesial and distal aspects were then averaged. Accordingly, the final analysis was based on four measurements per tooth-buccal, lingual, mesial and distal. The measurements were rounded to the nearest millimeter.

Following local anesthesia, the experimental teeth were scaled and root planed thoroughly with hand instruments. A No. 3 cowhorn explorer was used to check for smoothness of the surfaces of the teeth. After completion of scaling and root planing, the levels of the free gingival margin were marked buccally and lingually in both scaled and control teeth, using an inverted cone bur, in order to differentiate between supra and subgingival calculus after the extraction. The teeth were ex- 
tracted on the same day immediately after the experimental procedure. They were immediately rinsed with running water to remove any blood and soft tissue tags. The teeth were then transferred to $1 \%$ methylene blue for 2 minutes. This solution colored the connective tissue attached to the teeth and the plaque on the tooth surfaces. Finally, the teeth were rinsed with running water for 2 to 3 minutes.

The teeth were viewed under a stereomicroscope* with a magnification of $6.3 / 12.5$. The calculus present was assessed on four surfaces, (buccal, lingual, mesial and distal) using a Whipple Net Micrometer Disc, $\dagger 10 \mathrm{~mm}$ $\times 10 \mathrm{~mm}$ square, subdivided into 100 squares, which was placed on the eyepiece $\neq$ of the stereomicroscope. The four surfaces were separated by placing a small scratch with a curette on each line angle of the tooth, from the areas of the gingival landmark to the line of the connective tissue attachment. The total number of squares which covered each surface of the tooth from the connective tissue attachment to the free gingival margin scratch were counted. Only surface areas covering more than one-half of a square were counted as a square unit. These areas are shown as dotted areas on Figure 1. Then the number of squares with calculus for each of the surfaces was counted and added, indicating the total number of squares with calculus. No attempt was made to quantitate calculus within the furcation areas. A percentage of squares with calculus present was then obtained. In assessing calculus, the calculus present in each square of the tenth grid was counted as one, even if it was seen as a very small piece or a spot (Fig. 1).

Three measurements were taken of each surface by the same examiner at different times. All measurements showed a high level of reproducibility.

The statistical analysis was performed using the Michigan Interactive Data Analysis System (MIDAS).

The statistical tests applied were the Student $t$ Test, and correlation coefficients. Scatter plots were used to classify pocket depth (1-3 mm, 4-5 $\mathrm{mm}$ and 6 and above) and to show its correlation with the amount of calculus present.

\section{RESULTS}

The results of subgingival scaling and root planing on 62 scaled teeth were compared with similar data from 57 unscaled teeth from the same patients.

The correlations between percent of calculus left and pocket depth on scaled and unscaled teeth are recorded in Table 1. A high correlation was found between the above two variables on scaled teeth $(r=0.60, P<0.01)$. Also, a significant correlation was recorded between percent of calculus present and pocket depth on unscaled teeth $(r=0.50, P<0.01)$.

\footnotetext{
* J. M. Stereomicroscope, Olympus Optical Co. Ltd., Tokyo, Japan. $\dagger$ Micrometer Disc for Model J. M. Microscope, Olympus, Tokyo, Japan.

$\ddagger$ Eyepiece-WF $10 \times$ Micro-Optics Company, Southfield, MI.
}

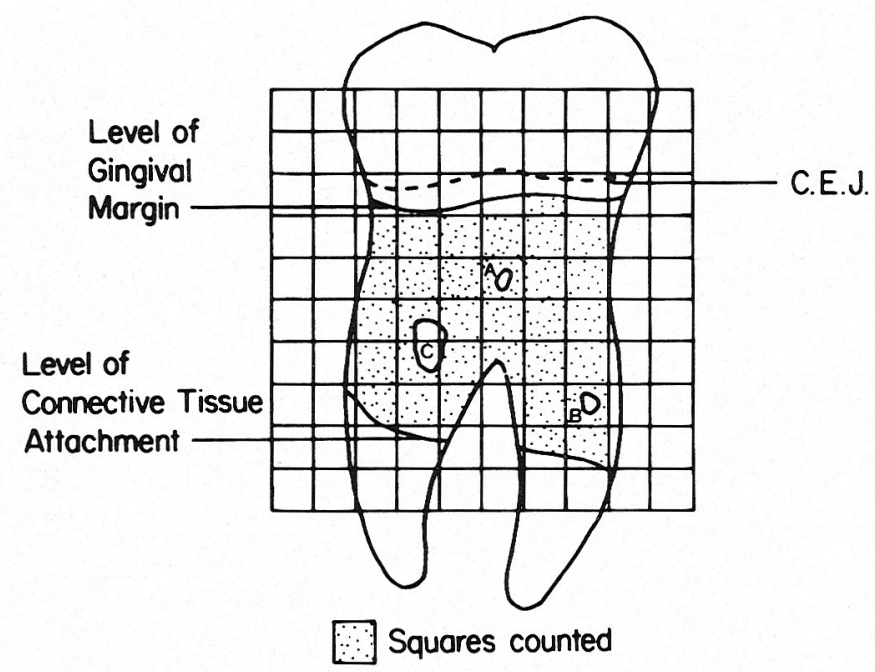

Squares not counted

A. One square with calculus

B. One square with calculus

C. Four squares with calculus

Total squares with calculus $=6$

Total squares covering surface $=32$

Percent calculus $=\frac{6}{32} \times 100$

Figure 1. Assessment of calculus under stereomicroscope.

Table 1

Correlation Between Percent of Calculus and Pocket Depth on Scaled and Unscaled Teeth

\begin{tabular}{llcc}
\hline Variable & $N$ & $r$ & $P$ \\
\hline Scaled & 62 & 0.60 & $<0.01$ \\
Unscaled & 57 & 0.50 & $<0.01$ \\
\hline
\end{tabular}

The correlations between percent of residual calculus left on scaled teeth and depth of pockets, according to different surfaces considered are shown in Table 2. A significant correlation was found. Table 3 shows the significant correlations found between percent of calculus present and pocket depth on unscaled teeth.

Figures 2 and 3 show the Scatter Plots relating percentage of calculus and mean pocket depths. These figures show that the percent of calculus increased with increasing pocket depths.

Anterior and posterior teeth were compared to find out if there was any difference in the percent of calculus found between them. Tables 4 and 5 present the mean differences in percent of calculus found when anterior and posterior teeth were considered. There were no statistically significant differences between anterior and posterior teeth when scaled or unscaled teeth were considered.

\section{DISCUSSION}

Earlier experimental studies have shown that a normal dental-epithelial junction can be re-established in areas 
Table 2

Correlation Between Percent of Residual Calculus and Pocket Depth on Scaled Teeth

\begin{tabular}{lccccccc}
\hline Surface & Variable & Mean & SD & $N$ & $r$ & $t$ & Sig. \\
\hline B & \% Calculus & 12.6 & 17.3 & 62 & 0.40 & 3.45 & 0.001 \\
& P.D. & 3.09 & 1.09 & & & & \\
L & \% Calculus & 15 & 19 & 62 & 0.50 & 4.50 & 0.000 \\
& P.D. & 4.14 & 2.05 & & & & \\
$\mathrm{M}^{*}$ & \% Calculus & 19.9 & 18.3 & 62 & 0.42 & 3.67 & 0.000 \\
& P.D. & 4.41 & 1.87 & & & & \\
$\mathrm{D} \dagger$ & \% Calculus & 18.8 & 16.4 & 62 & 0.32 & 2.67 & 0.009 \\
& P.D. & 4.38 & 1.47 & & & & \\
Tooth & \% Calculus & 17 & 13.4 & 62 & 0.59 & 5.76 & 0.000 \\
& P.D. & 4.01 & 1.40 & & & & \\
\hline
\end{tabular}

${ }^{*} \mathrm{M}=$ Average M.B. + M.L.

$\dagger \mathrm{D}=$ Average D.B. + D.L.

Table 3

Correlation Between Percent of Calculus and Pocket Depth on Unscaled Teeth

\begin{tabular}{lccccccc}
\hline Surface & Variable & Mean & SD & $N$ & $r$ & $t$ & Sig. \\
\hline B & \% Calculus & 36.2 & 31.9 & 57 & 0.32 & 2.53 & 0.014 \\
& P.D. & 3.03 & 1.25 & & & & \\
L & \% Calculus & 56 & 30.9 & 57 & 0.39 & 3.15 & 0.002 \\
& P.D. & 3.91 & 1.88 & & & & \\
$\mathrm{M}^{*}$ & \% Calculus & 56 & 33.2 & 57 & 0.44 & 3.65 & 0.000 \\
& P.D. & 4.28 & 1.37 & & & & \\
$\mathrm{D} \dagger$ & \% Calculus & 59.9 & 28 & 57 & 0.38 & 3.03 & 0.003 \\
& P.D. & 4.33 & 1.46 & & & & \\
Tooth & \% Calculus & 53 & 25 & 57 & 0.50 & 4.30 & 0.000 \\
& P.D. & 3.89 & 1.32 & & & &
\end{tabular}

${ }^{*} \mathrm{M}=$ Average M.B. + M.L.

$\dagger \mathrm{D}=$ Average D.B. + D.L.

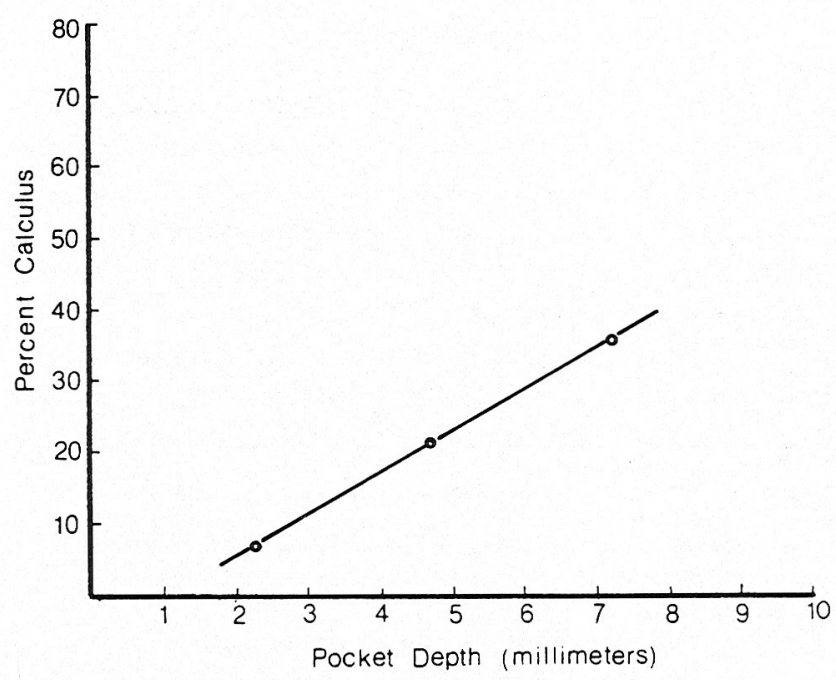

Figure 2. Scatter Plot---relation between percent of calculus and pocket depth on scaled teeth.

where all the subgingival plaque and calculus has been removed. ${ }^{6,7}$ However, the results of many other previous studies have indicated that complete removal of calculus from the root surfaces of teeth is difficult. ${ }^{1,2,8-11}$ The

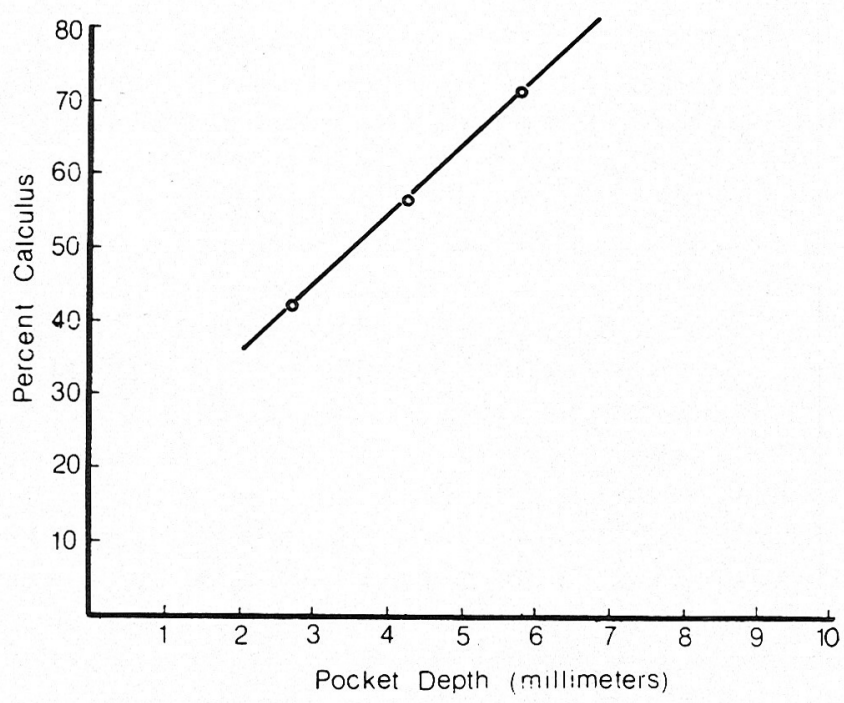

Figure 3. Scatter Plot-relation between percent of calculus and pocket depth on unscaled teeth.

findings in the present study are in agreement with these reports.

Schaffer ${ }^{11}$ scaled six teeth and root planed 12 others. He found that all six scaled teeth still had remaining 
Table 4

Comparison of Mean Differences of Percent of Residual Calculus Between Anterior and Posterior Scaled Teeth

\begin{tabular}{ccccccc}
\hline Surface & $N$ & Ant. $^{*}$ & Post. $\dagger$ & $t$ Test & DF & Sig. \\
\hline B & 62 & 12.9 & 12.2 & 0.15 & 60 & NS \\
L & 62 & 14.9 & 15 & -0.008 & 60 & NS \\
M & 62 & 19.6 & 20.3 & -0.13 & 60 & NS \\
D & 62 & 16.9 & 21 & -0.96 & 60 & NS \\
Tooth & 62 & 15.9 & 18.3 & -0.69 & 60 & NS \\
\hline
\end{tabular}

$* N=33$.

$\dagger N=29$.

Table 5

Comparison of Mean Differences of Percent of Calculus Between Anterior and Posterior Unscaled Teeth

\begin{tabular}{lllllll}
\hline Surface & $N$ & Ant. & Post. $\dagger$ & $t$ Test & DF & Sig. \\
\hline B & 57 & 38 & 34 & 0.48 & 55 & NS \\
L & 57 & 51.8 & 60.4 & -1.05 & 55 & NS \\
M & 57 & 50.9 & 61.6 & -1.2 & 55 & NS \\
D & 57 & 48 & 61.9 & -0.53 & 55 & NS \\
Tooth & 57 & 49.8 & 56.6 & -1.02 & 55 & NS \\
\hline \multicolumn{2}{r}{ N $=29}$. & & & & & \\
$\quad \dagger \mathrm{N}=28$. & & & & &
\end{tabular}

calculus after extraction. Remaining calculus was reported even over smoothed surfaces after root planing. ${ }^{8}$ When 48 subgingival root planed surfaces were inspected visually after extraction by Jones and O'Leary, ${ }^{2} 18.75 \%$ were found to have remaining visible flecks of calculus. Although the surfaces were inspected only visually, a high percent of remaining calculus was reported. Using different types of instruments, Jones et al. ${ }^{1}$ reported no difference in the efficiency of removal of calculus between the various instruments employed. Considerable amounts of calculus were found to be retained over some areas which were left clinically "smooth". It can be assumed that some of the causes of failure in subgingival scaling and root planing are due to lack of visual control.

The instrument which usually is used to ascertain the presence of calculus clinically is a sharp explorer guided by the sense of touch. This is not an accurate method in accomplishing the objective of assessing tooth surface characteristics. The explorer tip may not record differences between burnished calculus and the cementum. Thus, smooth burnished calculus may deceive the tactile sense of the operator using an explorer. In addition, calculus is likely to be inaccessible to the scaler if it is located in cemental crevices and resorption lacunae, in irregularities in the tooth surface and in furcations. In order to identify such deposits, it is necessary not only to explore every square micron of the planed surface but also to be able to detect differences between the calculus and the tooth surface. This is hard to achieve because of technical and anatomical problems which together make complete root planing difficult. Evaluation of the furcation entrance diameter of teeth has indicated that $58 \%$ of the furcation entrances of examined teeth were smaller than the blade face width of commonly used periodontal curettes. $^{12}$
Results of the present study using the stereomicroscope demonstrates that the deeper the pocket is, the greater is the chance of failure, which is in agreement with the results of previous studies. ${ }^{3,4}$ It has been suggested that complete removal of plaque and calculus in deep pockets (more than $5 \mathrm{~mm}$ ) is difficult. ${ }^{4}$ Re-establishement of a normal dento-epithelial junction is likely to occur in most pockets measuring less than $3 \mathrm{~mm}$. In pockets measuring between 3 and $5 \mathrm{~mm}$ the chances of failure becomes greater, and when pocket depth is more than 5 $\mathrm{mm}$ the chances of failure dominate. ${ }^{3}$ That the rate of failure increases with increasing pocket depth, could be expected. First, the amount of residual calculus may increase with the increase in size of the surface to be scaled. Second, as the pocket becomes deeper, more irregularities are usually observed on the tooth surfaces. ${ }^{3}$ Third, when the pocket gets deeper, the apical part of the pocket is narrower making accessibility to the bottom of the pocket difficult and the removal of calculus unlikely.

Numerous studies have shown that subgingival plaque and calculus are related to destructive periodontal disease. ${ }^{3,13-15}$ Therefore, the removal of bacterial plaque and calculus is an important aspect of all periodontal therapy. Considering the results of this and previous studies, which indicate problems related to complete scaling and root planing, it seems that supplemental treatment such as reflecting flaps should be used in treating deep pockets. However, the fact that scaling and root planing was accomplished in only one appointment for each patient in this study should be kept in mind. The results may have been improved if scaling and root planing had been repeated.

\section{CONCLUSIONS}

1. There is a statistically significant correlation $(r=$ $0.060 ; P<0.01$ ) between depth of pockets and percent of residual calculus following scaling and root planing.

2. There is a statistically significant correlation $(r=$ $0.050 ; P<0.01$ ) between pocket depth and percent of calculus present on unscaled teeth.

3. There is no statistically significant difference $(P>$ 0.05 ) between anterior and posterior teeth in the percent of residual calculus following scaling and root planing.

\section{REFERENCES}

1. Jones, S. J., Lozdan, J., and Boyde, A.: Tooth surfaces treated in situ with periodontal instruments. Scanning electron microscopic studies. $B$ Dent $J$ 132: 57, 1972.

2. Jones, W. A., and O'Leary, T. J.: The effectiveness of in vivo root planing in removing bacterial endotoxin from the roots of periodontally involved teeth. J Periodontol 49: 337, 1978.

3. Waerhaug, J.: Healing of the dento-epithelial junction following subgingival plaque control. II. As observed on extracted teeth. $J$ Periodontol 49: 119, 1978.

4. Lovdal, A., Arno, A., Schei, O., and Waerhaug, J.: Combined effect of subgingival scaling and controlled oral hygiene on the incidence of gingivitis. Acta Odontol Scand 19: 537, 1961.

5. Ramfjord, S. P.: Periodontal Disease Index (PDI). J Periodontol 38: 585, 1967. 
6. Waerhaug, J.: Microscopic demonstration of tissue reaction incident to removal of subgingival calculus. $J$ Periodontol 26: 26, 1955.

7. Wearhaug, J.: Healing of the dento-epithelial junction following subgingival plaque control. I. As observed in human biopsy material. J Periodontol 49: 1, 1978.

8. Frumker, S. C., and Gardner, W. M.: The relation of the root surface to the removal of calculus. J Periodontol 27: 292, 1956.

9. Moskow, B. S.: Calculus attachment in cemental separations. $J$ Periodontol 40: 125, 1969.

10. Meyer, K., and Lie, T.: Root surface roughness in response to periodontal instrumentation studied by combined use of microroughness measurements and scanning electron microscopy. J Clin Periodont 4: 77, 1977.

11. Schaffer, E. M.: Histological results of root curettage of human teeth. J Periodontol 27: 296, 1956.
12. Bower, R. C.: Furcation morphology relative to periodontal treatment. Furcation entrance architecture. J Periodontol 50: 23, 1979.

13. Ash, M. M., Jr., Gitlin, B. N., and Smith, W. A.: Correlation between plaque and gingivitis. $J$ Periodontol 35: 424, 1964.

14. Lovdal, A., Arno, A., and Waerhaug, J.: Incidence of clinical manifestations of periodontal disease in light of oral hygiene and calculus formation. J Am Dent Assoc 56: 21, 1958.

15. Waerhaug, J.: A method for evaluation of periodontal problems on extracted teeth. J Clin Periodont 2: 160, 1975.

Send reprint requests to: Dr. Raul G. Caffesse, Chairman, Department of Periodontics, The University of Michigan School of Dentistry, Ann Arbor, MI 48109.

\section{Announcements}

\section{THE UNIVERSITY OF PENNSYLVANIA SCHOOL OF DEN- TAL MEDICINE}

The University of Pennsylvania School of Dental Medicine announces the following continuing education courses:

Title: Periodontal Prosthesis: The Five-Day Program

DATE: April 12-16, 1981

Faculty: Morton AMSTERdaM, D.D.S., D. Walter Cohen, D.D.S., and Faculty

The Five-Day Program in Periodontal Prosthesis has been presented for over 25 years. Although this course has been given in an abbreviated format throughout the world, the Five-Day Program is offered only at Pennsylvania. This intensive and comprehensive course is designed to correlate periodontal therapeutics and advanced restorative procedures.

TITLE: The Hygienist as Periodontal Co-Therapist

DATE: May 9, 1981

Faculty: Norman Stoller, D.M.D., Associate Professor of Periodontics, University of Pennsylvania

Catherine Schifter, R.D.H., Assistant Professor of Dental Hygiene, University of Pennsylvania

To provide optimal care, hygienists must keep abreast with the latest changes and developments in periodontics. Designed for hygienists working with periodontists and with general practitioners.

TITLE: Periodontal Surgery I and II A Lecture and Participation Series

DATE: May 13-16, 1981

Faculty: Anthony C. Ruggerio, D.D.S., Assistant Professor of Periodontics, University of Pennsylvania

J. George Coslet, D.D.S., M.Sc.D., Associate Professor of Periodontics, University of Pennsylvania

$J_{\text {AY }}$ S. SeIBERT, D.D.S., Professor and Chairman of Periodontics, University of Pennsylvania

Two days of lecture with slide presentations of surgical techniques and two days of surgical participation. A unique opportunity to learn by actually doing surgical procedures.
Title: Treatment of Endo-Perio Lesions

Date: June 10, 1981

Faculty: D. Walter Cohen, D.D.S., Dean, School of Dental Medicine, University of Pennsylvania

Leif Tronstad, D.M.D., Ph.D., Chairman and Professor, Department of Endodontics, University of Pennsylvania

This course is designed to teach the clinician to recognize and treat combined endo-perio lesions. A clinical classification will be presented that will enable each clinician to diagnose, treat, and prognosticate what kind of healing to expect after treatment. A clear understanding of the biological principles basic to solving problems in treating the endo-perio lesion will be incorporated in this all day program utilizing lecture, slides, T.V. demonstrations, and blackboard seminars.

For further information please contact: Miss Susan Barnes, Continuing Education Center, University of Pennsylvania, School of Dental Medicine, 4001 Spruce Street, Philadelphia, PA 19104.

\section{PAPERS INVITED FOR BALINT ORBAN COMPETITION}

The 1981 Balint Orban Memorial Program of the AAP Annual Meeting in Toronto, October 21 , will provide an opportunity for students or recently trained periodontists to competitively present their own clinical or basic science research. The oral presentation will be 15 minutes with an additional 5 minutes for discussion. The winner of this competition, judged on the basis of oral presentation and submitted abstract, will receive a $\$ 200$ award and the paper will be published in the Journal of Periodontology. All other papers will be submitted to the editors for their consideration.

Students currently enrolled in an accredited Graduate or Postgraduate Program in Periodontology and those who have completed their training not more than 18 months before the AAP Annual Meeting are eligible. A curriculum vitae and abstract of not more than two double spaced typewritten pages are due no later than May 1, 1981. Those selected must also submit a manuscript suitable for publication by the time of the meeting.

Please send curriculum vitae and abstracts to: Dr. Russell Nisengard, S.U.N.Y. at Buffalo, School of Dentistry, 3435 Main Street, Buffalo, NY 14214. 